\title{
The TLNO/TLCO ratio in pulmonary function test interpretation
}

\author{
To the Editor:
}

HUGHES and VAN DER LEE [1] provide an excellent review of transfer factor of the lung for nitric oxide (TLNO)/transfer factor of the lung for carbon monoxide (TLCO) and highlight this ratio as a new lung function test in its own right. Perhaps we "TLNO enthusiasts" have overplayed TLNO as a route to DM (membrane diffusing capacity) and to $V_{c}$ (lung capillary volume) over the past three decades rather than thinking of it as a part of this ratio. HUGHES and VAN DER LEE [1] have rightly argued that TLNO/TLCO reflects $D \mathrm{M} / V_{c}$ and $\alpha$, the ratio of nitric oxide/carbon monoxide diffusivity.

Because TLCO is oxygen tension $\left(\mathrm{PO}_{2}\right)$ dependent and TLNO is not, I would also emphasise the importance of alveolar $\mathrm{PO}_{2}$ as a potential determinant of TLNO/TLCO in some of the studies they quote.

We found that TLNO/TLCO decreased from 4.5 to 3.8 in 10 healthy volunteers as alveolar oxygen per centwas decreased from 20 to $12 \%$ [2].This is entirely predictable from the review by HuGHES and VAN DER LEE [1] since specific conductance of blood for carbon monoxide ( $\Theta$ blco) increases with hypoxia, as they predicted (equation 8).

$$
\text { TLNO } / \mathrm{TLCO}=\alpha\left(1+D \mathrm{MCO} / \Theta \mathrm{blCO} \cdot V_{c}\right)
$$

Thus, in a healthy individual as breath hold time increases alveolar oxygen tension and, hence, TLNO/TLCO should fall. Again, on exercise, where most participants have used single breath or rebreathing methods, oxygen consumption rises with increasing workload, mean sampled alveolar $\mathrm{PO}_{2}$ falls steeply and hence TLNO/TLCO should fall. In disease we might expect lung units of high $D M / V_{c}$ to also have high alveolar ventilation $V^{\prime} \mathrm{A}$ /perfusion $\left(Q^{\prime}\right)$ and, therefore, high $\mathrm{PO}_{2}$. TLNO/TLCO will then increase as $\Theta \mathrm{CO}$ falls. This could contribute, along with increased $D \mathrm{M} / V_{c}$ to increased TLNO/TLCO observed in heavy smokers, certain diffuse pulmonary diseases, pulmonary hypertension and pulmonary artery hypertension. This argument always supposes that it is units of high $V^{\prime} \mathrm{A} / \mathrm{Q}^{\prime}$ that are being sampled. Conversely reduced lung expansion in restriction or in the obese would give low $V^{\prime} \mathrm{A} / Q^{\prime}$ and hence low TLNO/TLCO.

One final comment is that they state on a number of occasions that TLNO is independent of haemoglobin. This is correct in the strictest sense: theoretically and in clinical practice lung nitric oxide transfer does not vary with the haematocrits routinely encountered [3, 4]. However, if seriously low haemoglobin concentrations $\left(<8 \mathrm{~g} \cdot \mathrm{dL}^{-1}\right)$ are generated in the laboratory this can be shown to reduce the blood nitric oxide conductance [5].

0 @ERSpublications

The importance of alveolar oxygen tension as a potential determinant of TLNO/TLCO should be emphasised http://ow.ly/nZ67X

Colin Borland

Hinchingbrooke Hospital, Huntingdon, UK.

Correspondence: C. Borland, Hinchingbrooke Hospital, Huntingdon, UK. E-mail: colinborland@nhs.net

Received: Feb 072013 | Accepted: Feb 202013

Conflict of interest: None declared.

\section{References}

Hughes JM, van der Lee I. The TL,NO/TL,CO ratio in pulmonary function test interpretation. Eur Respir J 2013; 41: 453-461.

2 Borland CD, Cox Y. Effect of varying alveolar oxygen partial pressure on diffusing capacity for nitric oxide and carbon monoxide, membrane diffusing capacity and lung capillary volume. Clin Sci (Lond) 1991; 81: 759-765.

3 van der Lee I, Zanen P, Biesma DH, et al. The effect of red cell transfusion on nitric oxide diffusing capacity. Respiration 2005; 72: 512-516.

Zavorsky GS. No red cell resistance to NO? I think not! J Appl Physiol 2010; 108: 1027-1029.

Borland CD, Dunningham H, Bottrill F, et al. Can a membrane oxygenator be a model for NO and CO transfer? J Appl Physiol 2006; 100: 1527-1538. 